\title{
Medicated-Assisted Treatment and 12-Step Programs: Evaluating the Referral Process
}

Jacqueline Sharp, DNP, PMHNP-BC, Bobby Bellflower, DNSc, NNP-BC, FAANP \& Marthinus Zeeman, M.D. College of Nursing - The University of Tennessee Health Science Center - Memphis, TN

\section{Purpose}

- To compare abstinence rates among patients receiving medication- assisted treatment (MAT) who were referred to 12step programs to those only receiving MAT.

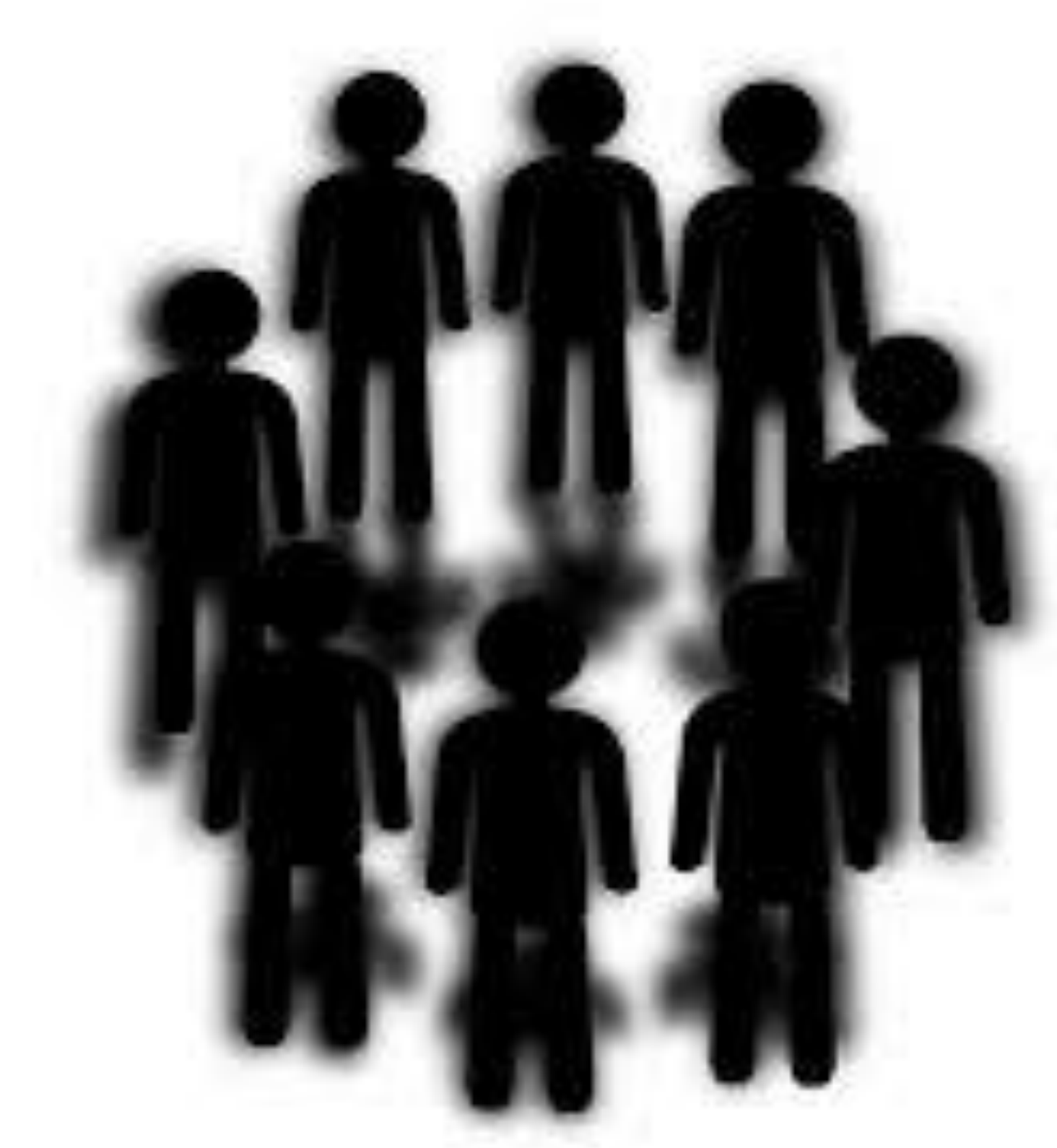

Background

- Overdose deaths in the U.S. from opioids have dramatically increased since the COVID-19 pandemic

- Although MAT programs are widely available for sufferers of opiate addiction, many drop out of treatment prematurely

- Twelve-step programs are considered a valuable part of treatment, but few studies have examined the effect of combining these approaches

\section{Methods}

- Experimental Design

- Prospective cohort study

- Study Population

-English-speaking, $\geq 18$ years

- DSM5 OUD diagnosis, on buprenorphine

- Primary Endpoint

- Change in positive UDS over 6 mo. between subjects and controls

\section{Results}

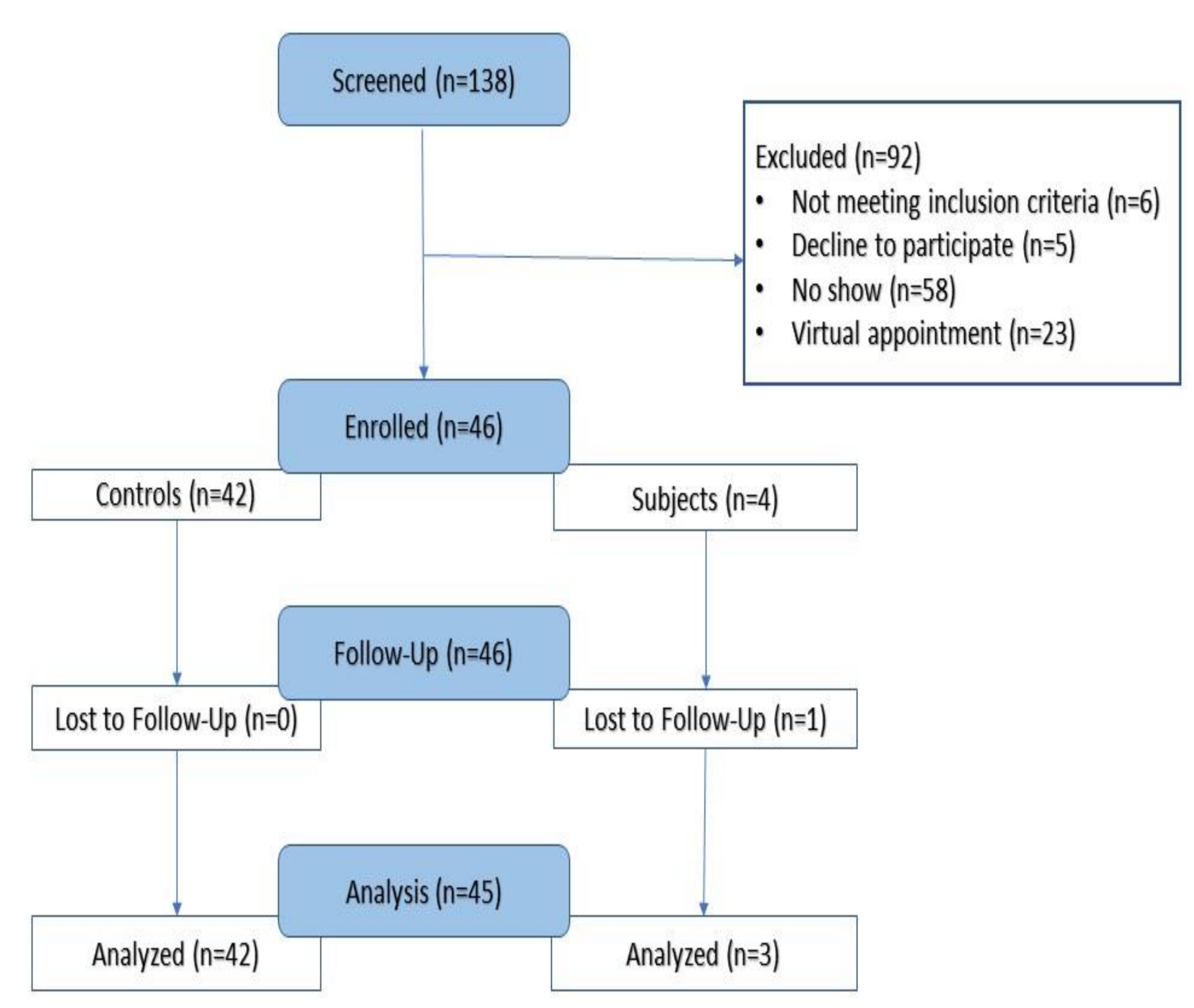

\section{Flow Diagram}

Enrollment Barriers

- Excluding new patients and those attending virtual visits

- High percentage of patients who missed appointments

- Lack of staff referrals

- Time constraints by both staff and patients
Implications for Practice

- Low enrollment limited our ability to determine whether combining medication management with a 12-step program improves abstinence.

- Failure to keep appointments is common among patients with OUD, and virtual meetings are becoming more prevalent post-COVID.

- Developing effective enrollment strategies is necessary to evaluate the effectiveness of combined treatment.

\section{References}

American Psychiatric Association. (2013a). Substance-related and addictive disorders. In Diagnostic and statistical manual of mental disorders (5th ed.), (pp. 481-590). Washington, DC: Author. Hayes, S. C., Wilson, K. G., \& Gifford, E. V. (2004). A preliminary report of twelve-step facilitation and acceptance and commitment therapy with polysubstance abusing methadone-maintained opiate addicts. Behavior Therapy, 35, 667-78.

https://doi.org/10.1016/S0005-7894(04)80014-5

Kampman, K., Jarvis, M. (2015). American Society of Addiction Medicine (ASAM) National Practice Guideline for the use of medications in the treatment of addiction involving opioid use. Journal of Addiction Medicine, 9(5), 358-367. https://doi.org/10.1097/ADM.000000000000166

Klein, A. A., \& Seppala, M. D. (2019). Medication-assisted treatment for opioid use disorder within a 12- step based treatment center: Feasibility and initial results. Journal of Substance Abuse Treatment, 104, 51-63. https://doi.org/10.1016/j.jsat.2019.06 Parron, T. V., Adelman, C. A., Merkin, B., Pagano, M. E., Defranco, R. Ionescu, R.,...Mace, A. G (2010). Long-term outcomes of officebased buprenorphine/naloxone maintenance therapy. Drug and Alcohol Dependence, 106, 56-60.

https://doi.org/10.1016/..drugalcdep.2009.07.013 